\title{
HIGH TEMPERATURE DEFORMATION OF INCONEL 718 CASTINGS
}

\author{
M.S. Lewandowski*, V. Sahai, R.C. Wilcox*, C.A. Matlock, and R.A. Overfelt
}

\author{
Space Power Institute \\ Auburn University \\ 231 Leach Center \\ Auburn, AL 36849 \\ * Materials Engineering Program \\ Mechanical Engineering Department \\ Auburn University \\ Auburn, AL 36849
}

\begin{abstract}
Computational models of solidification have proven to be very valuable to foundrymen in optimizing their casting processes. Current computer models can predict feeding characteristics, macroporosity formation, and even the development of grain structure in some alloys. However, stress related defects like hot tearing continuc to plaguc foundrics. Present research is attempting to incorporate stress analysis into the computational framework to better understand hot-tearing and related defects during casting. Proper mechanical constitutive relationships for the alloys of interest must be determined for the very high temperature deformation adjacent to and including the mushy zone of the casting. This paper presents the effects of temperature and strain rate on the compression response of Inconel 718 castings. The experimental data is compared with other investigations and potential constitutive relationships are reviewed. The observed mechanical behavior is discussed with respect to the underlying microstructural features and appropriate deformation mechanisms.
\end{abstract}




\section{Introduction}

Computational solidification modeling has matured from an interesting research tool to an important process design tool during the last few years. Many commercially supported computer programs are available for the foundryman to simulate the transient thermal field during cooling of complex castings. More sophisticated models today also simulate the fluid flows during casting, especially the all important filling of the mold. An increasing number of foundry engineers today utilize modeling technology to minimize the start-up times for new casting production and to maximize the yields from existing processes.

Foundry engineers exert control over casting processes by specifying alloy compositions, pouring temperatures, mold geometries, mold coatings, and mold temperatures. Knowledge of the predicted thermal behavior of the cooling casting coupled with an understanding of the solidification characteristics of the alloy enables the engineer to predict the development of many important microstructural features throughout the casting. The empirical basis of the alloy solidification behavior is often presented in "solidification maps" [1,2] or "defect maps" $[3,4]$. These empirical maps graphically represent the microstructural features (dendrite arm spacings, grain size, grain shape) and metallurgical defects for any given alloy as functions of the dominant thermal variables during casting: $G_{L}$ (thermal gradient in the liquid) and $V$ (growth front velocity). These parameters are usually determined from computational casting models that simulate the physics of the process. The foundry engineer can easily interrogate the computer model to yield the predicted cooling history of the casting, determine the numerically calculated $\mathrm{G}_{\mathrm{L}}$ and $\mathrm{V}$ at each point, and then assign the appropriate microstructural feature to that point in the casting from an empirical look-up table.

Computational analysis of casting conditions for the prediction of hot tears is a much more complicated problem because the thermal stresses and strains must be evaluated within the cooling casting. Researchers have been estimating thermally induced stresses and strains for years by first performing a thermal analysis and then using the calculated transient temperatures to drive a mechanical finite element analysis. The major shortcoming of this approach is the explicit uncoupling of the thermal and stress analyses and the inability to predict the critical gap formation at the metal-mold interface. Fully coupled solutions are the subject of research by several groups and significant progress is occurring. [5,6] Regardless of the approach, accurate constitutive relationships of high temperature deformation for the alloys of interest must be established.

Inconel 718 is a widely used superalloy in both wrought and cast forms. Srinivasan et $a l[7]$ developed a database of thermal and mechanical properties on wrought IN 718 to enable the computer simulation of forging of the alloy. Einpirical relationships for compression testing among the flow stress, temperature, and strain rate were developed for the strain rate range of 0.001 to $10 \mathrm{sec}^{-1}$ and the temperature range of $871^{\circ} \mathrm{C}$ to $1149^{\circ} \mathrm{C}$. Weis et al[8] and Guimaraes and Jonas[9] also utilized hot compression testing to investigate the high temperature deformation behavior of cast and wrought Inconel 718, respectively, in the following experimental regimes: $950-1150^{\circ} \mathrm{C}: 0.01-1.0 \mathrm{sec}^{-1}$ and $875-1090^{\circ} \mathrm{C}: 5.6 \times 10^{-4}$ $9.3 \times 10^{-2} \mathrm{sec}^{-1}$, respectively. Each of the investigations reported that the compression data exhibited a peak in the flow stress followed by extensive strain softening at the lowest temperatures whereas at the highest temperatures constant flow stresses were reported. In addition, Weis et al[8] and Guimaraes and Jonas[9] also noted that the compression response 
included yield point behavior at the lowest strain rates. Srinivasan et al[7] did not report any yield point effects.

Hot tensile data on as-cast materials was considered inappropriate to accurately assess the high temperature constitutive relationships since tensile tests would open any latent porosity and invalidate the results. Hot compression tests are necessary in the solid state and tensile tests are required on samples in the mushy zone. This paper reports on the first phase, hot compression testing, of an experimental investigation of the high temperature deformation of as cast Inconel 718.

\section{Materials and Experimental Procedure}

One heat of Inconel 718 of composition $54.7 \% \mathrm{Ni}, 18.3 \% \mathrm{Cr}, 18.9 \% \mathrm{Fe}, 4.6 \% \mathrm{Nb}, 2.0 \%$ Mo, and $0.83 \% \mathrm{Ti}$ (weight percents) was used for this study. The samples were investment cast at Howmet Corporation, Whitehall, MI. The elevated temperature compression tests were conducted with a Gleeble 1500 apparatus and the $12.4 \mathrm{~mm}$ diameter by $12 \mathrm{~mm}$ long samples were tested in vacuum. Test temperatures were measured with a Type $\mathrm{K}$ thermocouple welded to the compression sample. Specimens were directly resistively heated to the test temperature at a rate of $25^{\circ} \mathrm{C}$ per minute and then held for 5 minutes before compression testing was initiated. Three samples at each of three temperatures, $950^{\circ} \mathrm{C}, 1000^{\circ} \mathrm{C}$, and $1050^{\circ} \mathrm{C}$ and three strain rates, $0.01,0.001$, and $0.0001 \mathrm{sec}^{-1}$ were utilized. All testing utilized compression and all compression strains are reported with positive (rather than negative) values.

Standard metallographic procedures were used to section, grind, and polish samples for optical microscopy. All metallographic samples were electro-etched in a solution of $85 \% \mathrm{H}_{2} \mathrm{O}$, $10 \% \mathrm{HNO}_{3}$, and $5 \%$ acetic acid. Figure 1 shows a typical as-received, investment cast IN 718 bar used in this investigation. The samples exhibited a random orientation of grains which should produce isotropic compression properties and low levels of microporosity.

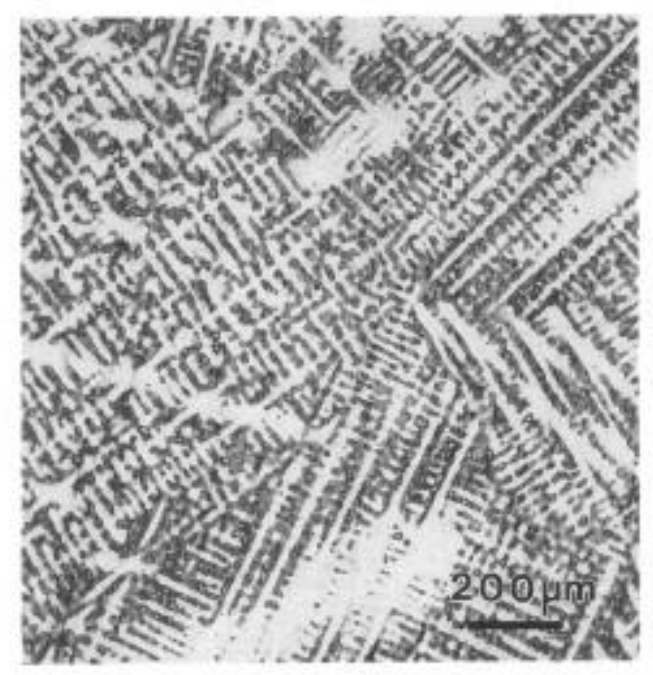

(a)

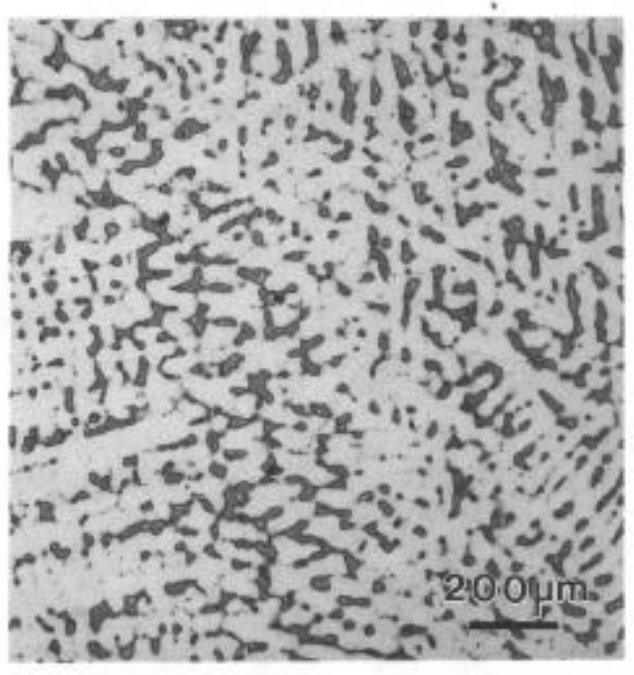

(b)

Figure 1. Macroetched sections of as-cast Inconel 718 bar used for the hot compression testing. (a) transverse, (b) longitudinal

All temperature, axial force, and sample length data were recorded on a computer data acquisition system sampling at approximately $40 \mathrm{~Hz}$. The compression tests were conducted 
until a nominally constant stress was obtained. When a constant flow stress was reached, the last 200 data points (from a data set of 935-3600 depending upon strain rate) were used to obtain the compressive flow stress. Calculations of the stress were based upon the instantaneous area of the mid-section of the compression specimen during the test. The coefficient of thermal expansion of Inconel 718 at $93^{\circ} \mathrm{C}$ is $1.28 \times 10^{-5}{ }^{\circ} \mathrm{C}^{-1}$ and at $1093^{\circ} \mathrm{C}$ is $1.78 \times 10^{-5}{ }^{\circ} \mathrm{C}^{-1} \cdot[10]$ A linear relationship of expansion coefficient was assumed between these temperatures. The instantaneous area was calculated based upon three assumptions. (1) The volume of the sample was constant at all times. (2) The side of the sample deformed in the shape of an ellipse in which the major axis was equal to half of the instantaneous sample length. (3) The friction between the sample ends and the Gleeble platen was so great that the diameter of the sample in contact with the platens did not change.

\section{Results}

\section{Hot Compression Testing}

Typical experimental curves of hot compression true stress-true strain data are shown in Figures 2, 3, and 4 for strain rates of $0.01,0.001$, and $0.0001 \mathrm{sec}^{-1}$, respectively. Data are shown in each figure for test temperatures of $950^{\circ} \mathrm{C}, 1000^{\circ} \mathrm{C}$, and $1050^{\circ} \mathrm{C}$. At a true strain rate of $0.01 \mathrm{sec}^{-1}$ (Figure 2), the samples deformed to a maximum stress which then slowly decreased with increasing strain indicating that substantial strain softening was occurring. The peak flow stress varied from $100 \mathrm{MPa}$ at $1050^{\circ} \mathrm{C}$ to $140 \mathrm{MPa}$ at $950^{\circ} \mathrm{C}$. In addition, the sample tested at $950^{\circ} \mathrm{C}$ also exhibited a slight yield point drop. Strain softening was not observed in the samples investigated at a strain rate of $0.001 \mathrm{sec}^{-1}$ (Figure 3 ) for the range of total true strains investigated of between 0.15 and 0.20 . Although the behavior and flow stress of the samples tested at temperatures of $950^{\circ} \mathrm{C}(103 \mathrm{MPa})$ and $1000^{\circ} \mathrm{C}(95 \mathrm{MPa})$ were quite similar, the samples tested at $1050^{\circ} \mathrm{C}$ produced a significantly lower flow stress (50 MPa). None of these samples exhibited yield point drops. At a true strain rate of $0.0001 \mathrm{sec}^{-1}$ (Figure 4), the samples exhibited a rclatively constant flow stress although a minor amount of strain softening may have occurred toward the end of each test. The maximum flow stresses observed at $0.0001 \mathrm{sec}^{-1}$ ranged from $22 \mathrm{MPa}\left(1050^{\circ} \mathrm{C}\right)$ to $40 \mathrm{MPa}\left(950^{\circ} \mathrm{C}\right)$.

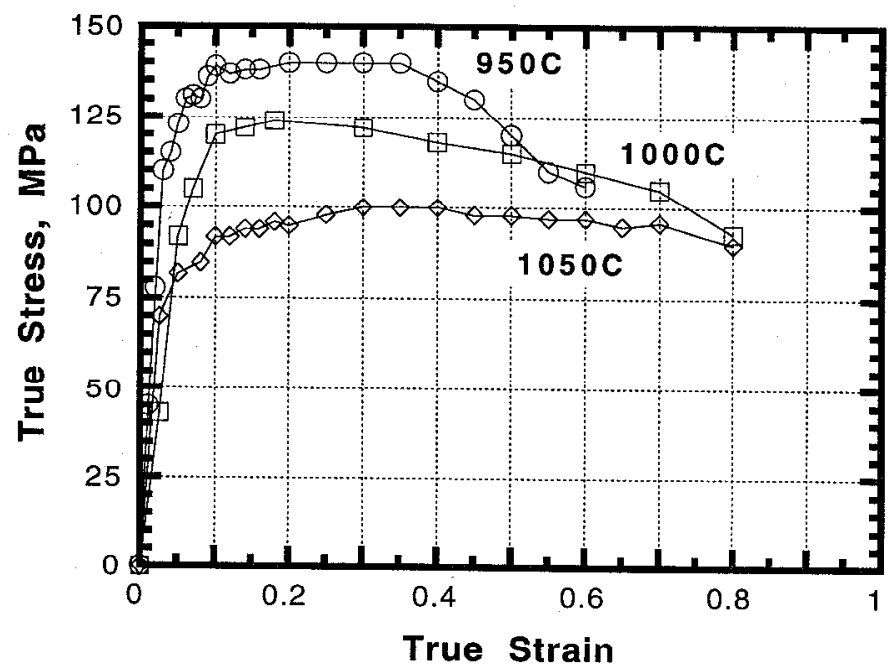

Figure 2. True stress - true strain compression flow curves for as-cast Inconel 718 deformed at at a true strain rate of $0.01 \mathrm{sec}^{-1}$ at the indicated test temperatures. 


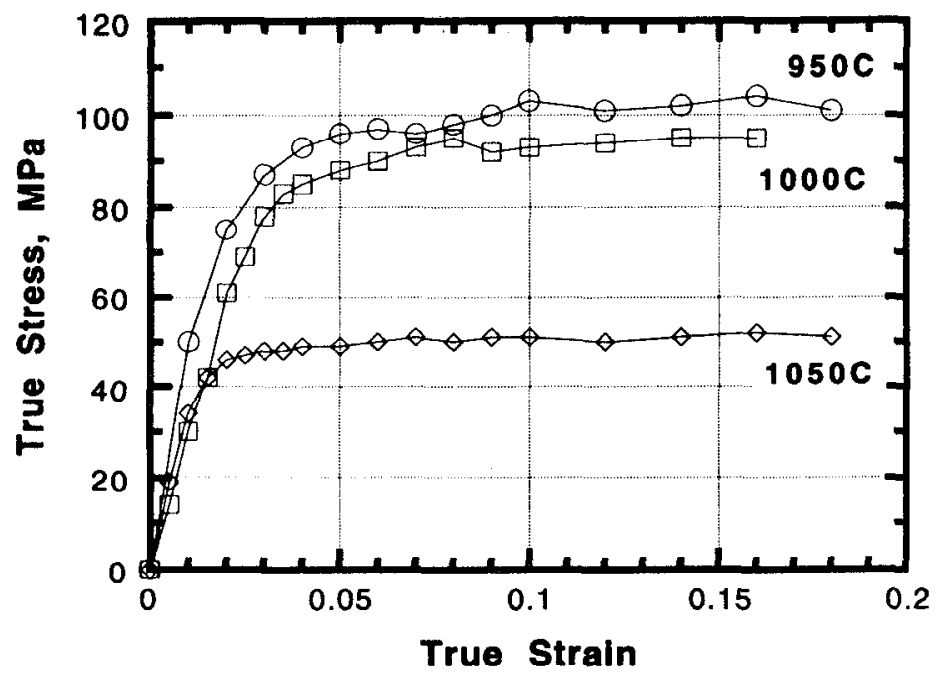

Figure 3. True stress - true strain compression flow curves for as-cast Inconel 718 deformed at at a true strain rate of $0.001 \mathrm{sec}^{-1}$ at the indicated test temperatures.

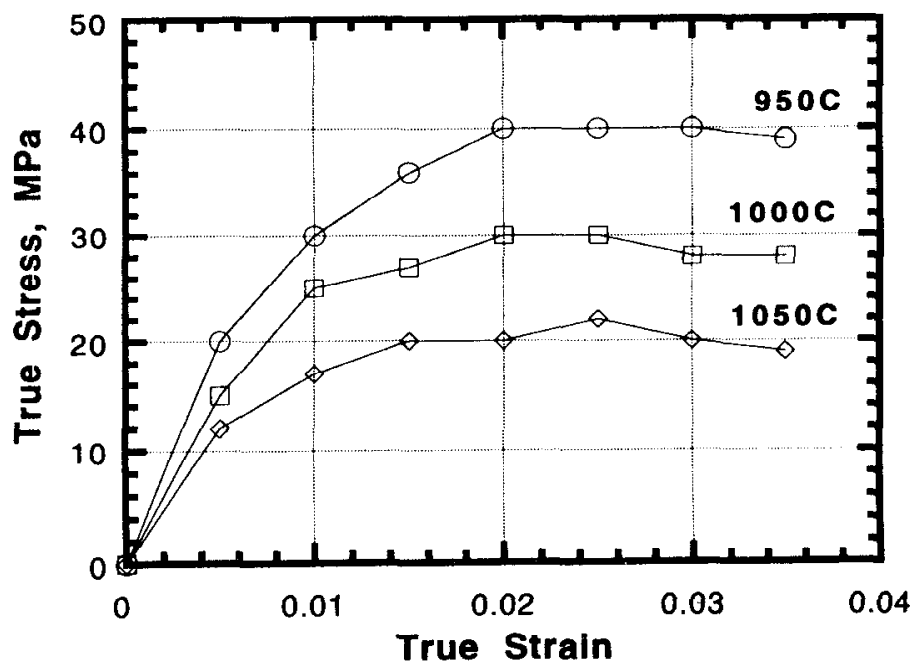

Figure 4. True stress - true strain compression flow curves for as-cast Inconel 718 deformed at at a true strain rate of $0.0001 \mathrm{sec}^{-1}$ at the indicated test temperatures.

The temperature dependent peak flow stress data for each strain rate are summarized in Figure 5. The maximum flow stress decreased with increasing test temperature and decreasing strain rate as expected. The maximum flow stresses generally agree with previous work on cast and wrought samples of Inconcl 718 as discussed bclow.

Weis et al[8] show that high temperature compression data can often be adequately described by an equation of the form

$$
\sigma=\left(\frac{1}{A} \dot{\varepsilon} \exp \left(\frac{Q}{R T}\right)\right)^{1 / n}
$$

where $\sigma$ is the true stress, $A$ is an alloy constant, $\bar{\varepsilon}$ is the strain rate, $Q$ is the activation energy for the deformation process, $R$ is the gas constant, $T$ is the absolute temperature, and $n$ is the stress exponent. The quantity $\dot{\varepsilon} \exp (Q / R T)$ is frequently referred to as the temperature 
Higure 5. 'The effects of test temperature and strain rate on the maximum true flow stress in as-cast Inconel 718.

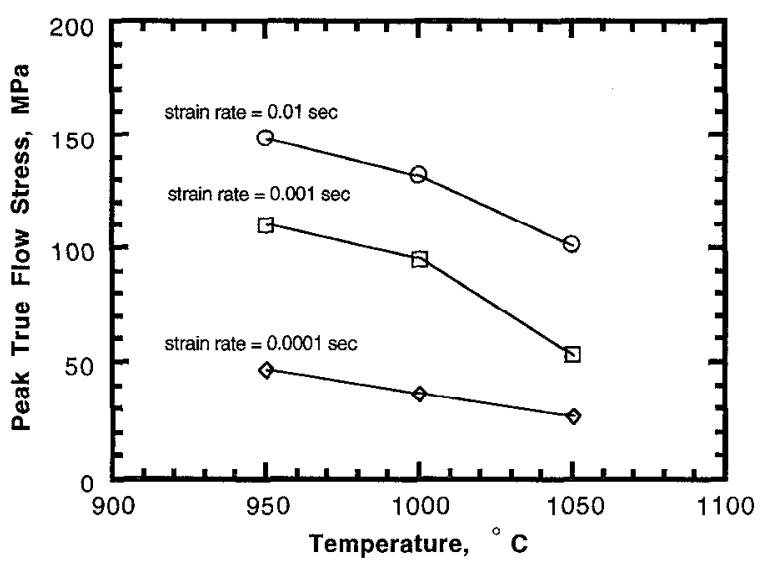

compensated strain rate or the Zener-Holloman parameter. Weis et al[8] found the activation energy for the high temperature deformation of Inconel 718 to be $423 \mathrm{~kJ} / \mathrm{mole}$. If Eq. [1] adequately represents the data from all of these investigations, then a log-log plot of the maximum true flow stress versus the Zener-Holloman parameter should yield a straight line. Figure 6 shows such a plot from the data of Srinivasan et al[7], Weis et al[8], Guimaraes and Jonas [9], Garcia et al[11], DiConza et al[12], and the current investigation. Two distinct experimental behaviors are readily apparent in Figure 6. The literature data and the data from this investigation exhibit relatively good agreement, except that the peak true flow stress data from this investigation generally fall on the low side of the bandwidth of the aggregated data. Possible reasons for this behavior are assessed in the Discussion section of this paper.

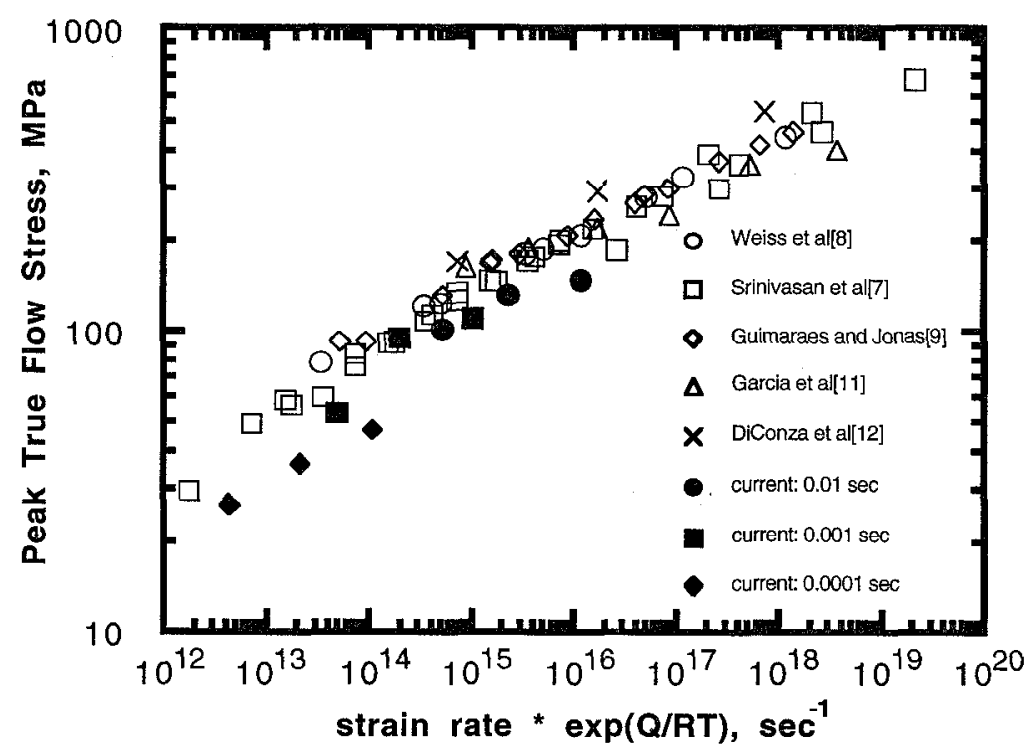

Figure 6. Maximum true flow stress versus the Zener-Holloman parameter for the hot compression data of Srinivasan et al[7], Weis et al [8], Guimaraes and Jonas [9], Garcia et al[11], DiConza et al[12], and this investigation. 
Although the experimental results shown in Figure 6 exhibit considerable scatter, a best fit line was evaluated for utilization in computational models of stress vs. strain. Using $Q=423$ $\mathrm{kJ} / \mathrm{mole}$ as determined by Weis et al[8], the coefficients of the best fit line per Eq. (1) were determined to be $A=7440$ and $n=5.30$ with a correlation coefficient of 0.966 .

\section{Microstructural Analysis}

The microtructure of a sample tested at $1050^{\circ} \mathrm{C}$ and $0.01 \mathrm{sec}^{-1}$ is shown in Figure 7. Stringers of the original Laves phases and equiaxed recrystallized grains within the original dendrites are clearly visible. Guimaraes and Jonas[9] reported that dynamic recrystallization was observed for total true strains greater than 0.4 for temperatures and strain rates similar to those used in the current investigation. In the experiments being reported here, samples tested at $0.01 \mathrm{sec}^{-1}, 0.001 \mathrm{sec}^{-1}$, and $0.0001 \mathrm{sec}^{-1}$ experienced total true strains of approximately 0.7 , 0.17 , and 0.035 , respectively, and equiaxed recrystallization was observed in all samples. Unfortunately the compression testing could not be interrupted for quenching of the samples in the Gleeble 1500 's vacuum system.

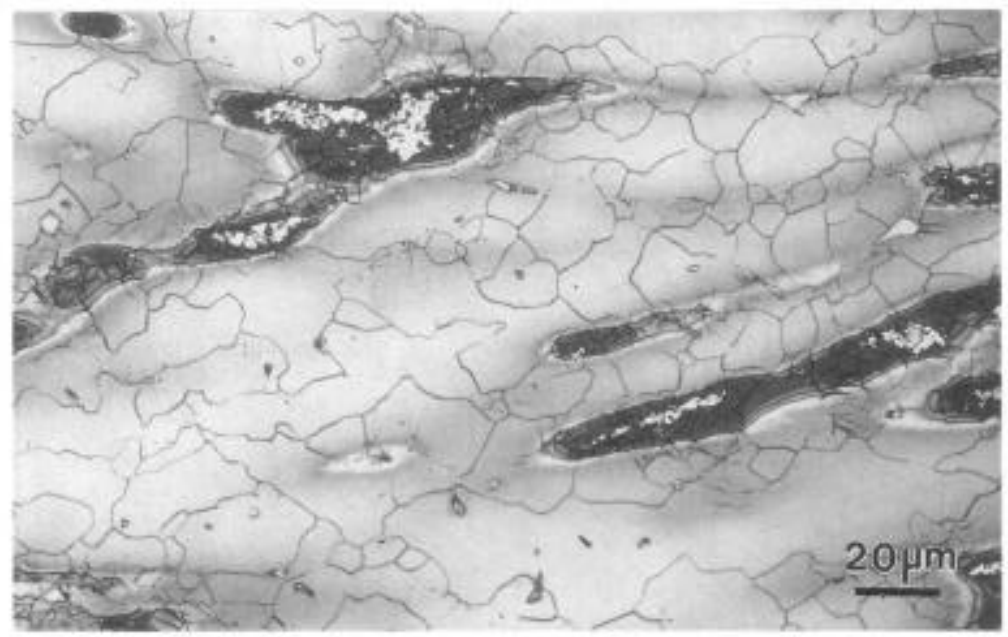

Figure 7. Longitudinal micrograph of the sample strained at $1050^{\circ} \mathrm{C}, 0.01 \mathrm{sec}^{-1}$, and total strain of 0.8 showing recrystallized grains within the highly deformed original dendritic structure. Stringers of the original Laves phases are also clearly present.

All compression samples were longitudinally sectioned, polished and etched as noted above. Figure 8 shows typical samples from the hot compression experiments after termination of each experiment. The temperatures, strain rates, and total true strains experienced by each sample are also given. Samples tested at the lowest strain rates and lowest total true strains clearly exhibit remnants of the original dendritic structure. In fact, some of these samples appear to have incurred very little damage to the original dendritic structure. However, samples tested at the highest strain rates and greatest total true strains suffered severe deformation of the original dendritic structure.

\section{Discussion}

The peak true flow stresses determined in this investigation are consistently lower than those obtained by other investigators. One possible reason for this exists in the methodology utilized to determine the true area for stress calculations. Previous investigators[7-9,11,12] 


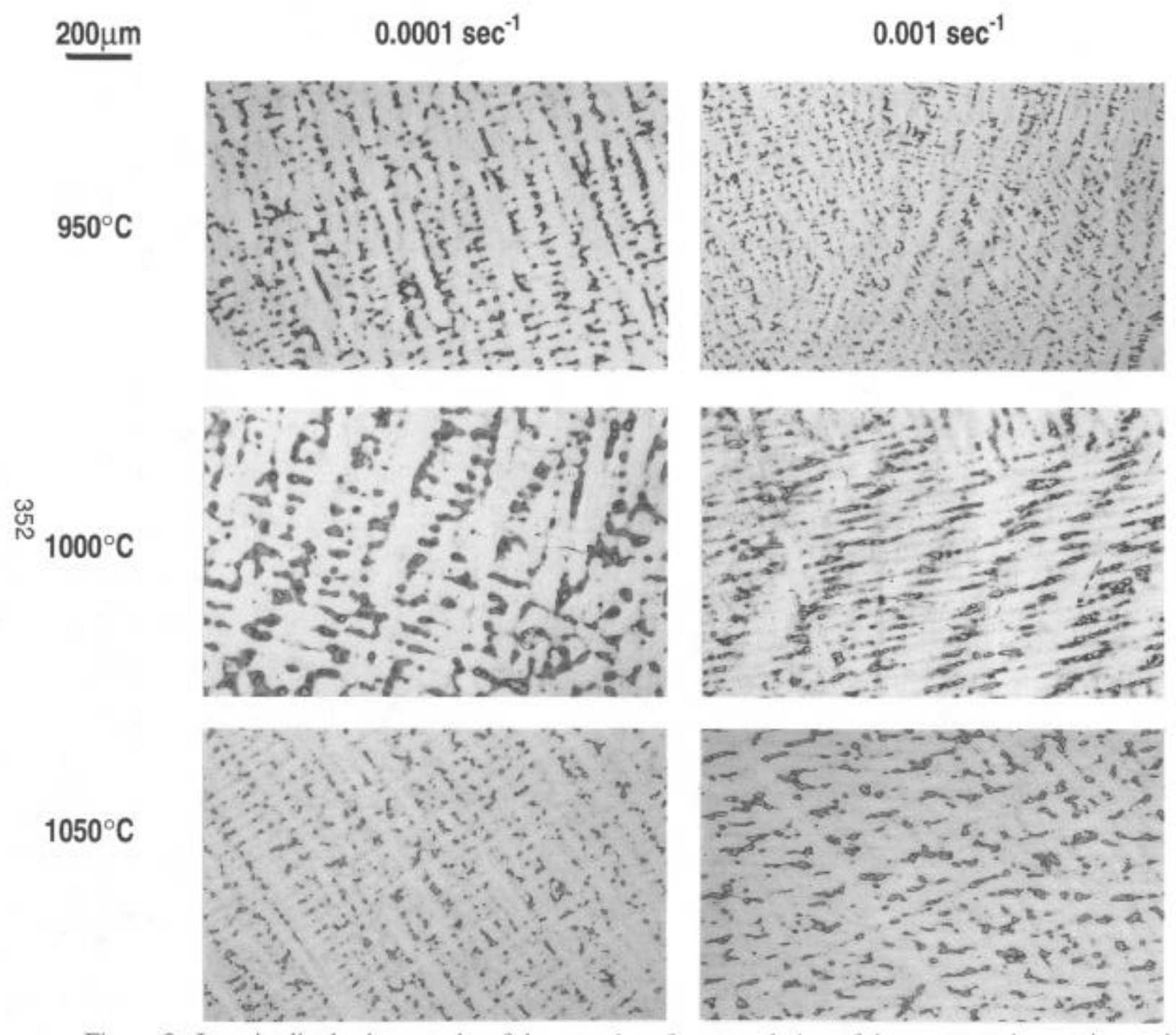

Figure 8. Longitudinal micrographs of the samples after completion of the compression testing at the indicated temperatur 
have used standard tensile testing machines modified for high temperature compression. In such machines, the sample is held in the vertical position and the compression stroke is also vertical. Thus, powder lubricants like glass could be used to allow the sample to expand more freely between the test sample and the compression platens. This would result in less barreling of the samples. Some of the researchers $[8,9,11]$ also machined grooves or recesses in the ends of the samples to containe the powder lubricants. None of the investigations reported the details of how they actually calculated the areas. Readers are left to assume that barreling effects were neglected, constant volumes were maintained, and the areas increased uniformly with decreasing sample lengths. Unfortunately, none of the investigations reported on whether their use of lubricants actually eliminated barreling effects from their samples. Barreling was present in the samples reported here and further evaluation of this effect is continuing.

Significant strain softening and recrystallization was only observed in samples tested at $0.01 \mathrm{sec}^{-1}$ at $1000^{\circ} \mathrm{C}$ and $1050^{\circ} \mathrm{C}$. Guimaraes and Jonas[9] suggested that adiabatic heating of the samples was partially responsible for strain softening effects. Weis et al[8] used interrupted and quenched tests to evaluate several possible mechanisms for strain softening effects in their tests and concluded that dynamic recovery coupled with a small amount of adiabatic heating dominated the softening behavior. However, in our experiments, the samples were resistively heated directly and the amount of power supplied to the sample was controlled by a thermocouple welded to the midpoint of the surface of the sample. Adiabatic heating could not have been a significant cause of the softening behavior in our experiments. Thus dynamic recovery was likely the dominant mechanism.

Garcia et al[11] noted that the recrystallization process in Inconel 718 began with twinning. No evidence of twinning was seen in the microstructures of the samples tested in this investigation in agreement with Weis et al's results on interrupted and quenched samples. The equiaxed nature of the recrystallized grains seen in this investigation suggests that recrystallization observed occurred after the end of the dcformation testing as the samples were cooling to room temperature, i.e. via static rather than dynamic recrystallization. Since the compression testing could not be interrupted for quenching of the samples in the vacuum system of the Gleeble 1500, it was not possible to separate static versus dynamic recrystallization effects in our experiments.

\section{Conclusions}

1. The flow stress in as-cast Inconel 718 is both strain rate and temperature dependent, and increases with increasing strain rate and decreasing temperature.

2. The peak true flow stress of Inconel 718 can be represented by the following equation:

$$
\sigma=\left(\frac{1}{A} \dot{\varepsilon} \exp \left(\frac{Q}{R T}\right)\right)^{1 / n}
$$

where $A=7440, n=5.30, Q=423 \mathrm{~kJ} / \mathrm{mole}$, and $R$ is the universal gas constant.

3. Friction effects at the sample-platen interface and the resulting barreling in samples significantly affects calculated stresses due to uncertainty in the actual area of the sample undergoing compression. Noncontact extensometer techniques are recommended to accurately measure the changes in sample geometry during testing.

4. Strain softening was observed in samples tested at $\dot{\varepsilon}=0.01 \mathrm{sec}^{-1}$ at temperatures of $1000^{\circ} \mathrm{C} \& 1050^{\circ} \mathrm{C}$. Adiabatic heating of the samples was not responsible for this effect. 


\section{Acknowledgements}

The authors gratefully acknowledge the financial support received from ARPA under Agreement No. MDA972-93-2-0001 and from the Investment Casting Cooperative Arrangement chaired by Howmet Corporation, Whitehall, MI.

\section{References}

[1] N. Tsumagari, C.E. Mobley, and P.R. Gangasani, "Construction and Application of Solidification Maps for A356 and D357 Aluminum Alloys," Paper No. 93-119, presented at the AFS 97th Casting Congress, April 24-27, 1993, Chicago, IL.

[2] P.N. Quested and M. McLean, "Solidification Morphologies in Directionally Solidified Superalloys," Mater. Sci. \& Eng., Vol. 65, p. 171, 1984.

[3] J.S. Tu \& R.K. Foran, "The Application of Defect Maps in Process Modeling of Single Crystal Investment Casting," JOM, Vol. 44, No. 6, p. 26, 1992.

[4] K.O. Yu, J.J. Nichols, and M. Robinson, "Finite-Element Thermal Modeling of Casting Microstructures and Defects," IOM, Vol. 44, No. 6, p. 20, 1992.

[5] Mark Cross, "Development of Novel Computational Techniques for the Next Generation of Software Tools for Casting Simulation," Modeling of Casting, Welding and $\Lambda$ dvanced Solidification Processes - VI, eds. T.S. Piwonka, V. Voller, and L. Katgerman (Warrendale, PA: The Metallurgical Society, 1993), 115-126.

[6] Arthur Shapiro, Werner Stein, and Peter Raboin, "Casting Process Modeling Using ProCAST and CAST2D," Modeling of Casting. Welding and Advanced Solidification Processes - VI, eds. T.S. Piwonka, V. Voller, and L. Katgerman (Warrendale, PA: The Metallurgical Society, 1993), 493-500.

[7] R. Srinivasan, V. Ramnarayan, U. Deshpande, V. Jain, and I. Weiss, "Computer Simulation of the Forging of Fine Grain IN-718 Alloy," Met. Trans. A, 24A (1993), 2061-2069.

[8] M. J. Weis, M.C. Mataya, S.W. Thompson, and D.K. Matlock, "The Hot Deformation Behavior of an As-Cast Alloy 718 Ingot," Superalloy 718 - Metallurgy and Applications, ed. E.A. Loria, (Warrendale, PA: The Metallurgical Society, 1989), 135-154.

[9] A.A. Guimaraes and J.J. Jonas, "Recrystallization and Aging Effects Associated with the High Temperature Deformation of Inconel 718," Met. Trans. A, 12A (1981), 1655-1666.

[10] Sulckh C. Jain, private communication with the authors, General Electric Aircraft Engines, June 1993.

[11] C.I. Garcia, D.E. Camus, E.A. Loria, and A.J. DeArdo, "Microstructural Refinement of As-Cast Alloy 718 via Thermomechanical Processing," Superalloys 718, 625, and Various Derivatives, ed. E.A. Loria, (Warrendale, PA: The Metallurgical Society, 1991), 925-941.

[12] Paul J. DiConza, Ronald R. Biederman, and Rishi P. Singh, "Homogenization and Thermomechanical Processing of Cast Alloy 718," ibid, 161-171. 